\title{
Simulation of Floc Size Distribution in Flocculation of Activated Sludge Using Population Balance Model with Modified Expressions for the Aggregation and Breakage
}

\author{
Zhenliang Li ${ }^{1}{ }^{1}$ Peili Lu $\mathbb{D}^{2,3}$ Daijun Zhang, ${ }^{2,3}$ and Fuzhong Song ${ }^{2,3}$ \\ ${ }^{1}$ Chongqing Research Academy of Environmental Sciences, Chongqing 401147, China \\ ${ }^{2}$ State Key Laboratory of Coal Mine Disaster Dynamics and Control, Chongqing University, Chongqing 400044, China \\ ${ }^{3}$ Department of Environmental Science, Chongqing University, Chongqing 400044, China \\ Correspondence should be addressed to Peili Lu; lupl@cqu.edu.cn
}

Received 12 April 2019; Revised 26 June 2019; Accepted 9 July 2019; Published 22 July 2019

Academic Editor: Ricardo Aguilar-Lopez

Copyright (C) 2019 Zhenliang Li et al. This is an open access article distributed under the Creative Commons Attribution License, which permits unrestricted use, distribution, and reproduction in any medium, provided the original work is properly cited.

\begin{abstract}
The floc size distribution of activated sludge was simulated successfully by population balance model in the previous study (Population Balance Model and Calibration Method for Simulating the Time Evolution of Floc Size Distribution of Activated Sludge Flocculation. Desalination and Water Treatment, 67, 41-50). However, nonignorable errors exist in the simulation for the volume percentage of large flocs. This paper describes the application of a modified population balance model in the simulation of the time evolution of floc size distribution in activated sludge flocculation process under shear-induced conditions. It was found that the application of modified size dependent collision efficiency, modified breakage rate expression by assuming a maximum value, and binominal daughter-particles distribution function could improve the population balance model for activated sludge flocculation and successfully predict the dynamic changes in volume percentage distribution and mean floc size of activated sludge under different shear conditions. The results demonstrate that the maximum breakage rate was independent on the velocity gradient, and both the collision efficiency and breakage rate coefficient show a power-law relationship with the average velocity gradient; the former decreases while the latter increases with the rise of the average velocity gradient. These findings would help to understand the dynamics of activated sludge flocculation.
\end{abstract}

\section{Introduction}

Activated sludge process is the most widely used technology for biologically treating wastewater, in which the separation of activated sludge from the effluent is an essential step. The formation of activated sludge flocs through flocculation plays a determinant role in achieving high separation efficiency. If flocculation fails to occur, active biomass would be lost from the system, resulting in not only excess solids being discharged into the environment, but also reduced process efficiency. Therefore, the study on the flocculation dynamics of activated sludge is significant to gain further understanding of the formation of bioflocs.

Flocculation can be regarded as a competition between aggregation and breakage. The mathematical modeling of flocculation usually makes use of the population balance model (PBM). In the PBM the flocculation dynamics are simulated by the change in floc size distribution (FSD) that is induced by simultaneous aggregation and breakage $[1,2]$. The modelling of shear-induced flocculation of inorganic particles, such as polystyrene particles [3-5], latex microsphere $[2,6,7]$, precipitated calcium carbonate (PCC) [8], and suspension of kaolinite or bentonite [9-12] has been widely reported. These studies focused on the prediction of the change in mean floc size and the steady-state FSD where aggregation and breakage were counterbalanced. In addition, the PBM was also used in modeling the flocculation of natural flocs or mud existing in marine or estuarine sediment ecosystems [13-15].

Different from the inorganic shear-induced flocculation processes, the flocculation of activated sludge is affected by various factors, including the floc's physical and chemical 
characteristics and the external environmental conditions, such as dissolved oxygen, $\mathrm{pH}$, etc. [16-18]. Consequently, discrepancies between the predicted and measured results of activated sludge flocculation have always been observed [19-22]. To achieve better modeling, the appropriate models for the aggregation and breakage of activated sludge are the key "issues." By comparing 16 models with different sizedependent aggregation and breakage expressions, Ding et al. [21] suggested the model for the best description of the dynamic changes in the mass distribution of activated sludge under different shear. However, the relationship between the kinetic parameters and the shear rate might not follow the expected physical relationships. Nopens et al. [23] and Torfs et al. $[24,25]$ proposed solving the inverse problem as an alternative way to get a grip on the different expressions for aggregation of activated sludge. Although these simulation studies provided valuable findings on the failure of the existing expressions for aggregation to capture the true dynamics, selecting (or developing) appropriate kinetic expressions for aggregation or breakage is still the challenge when the PBM is used to model the flocculation of activated sludge [26].

In our previous study [22], error was found in simulating the volume percentage of large flocs (about larger than $200 \mu \mathrm{m}$ ) of activated sludge flocculation by PBM, which results in smaller simulated mean sizes than their measurements. This work aims to improve the PBM to accurately simulate the time evolution of FSD in the flocculation process of activated sludge. For this purpose, the size-dependent expressions for collision efficiency and breakage rate were modified, the fractal dimension of activated sludge was introduced in modeling collision frequency and breakage rate, and a binominal function was proposed to describe the daughter-particles distribution after floc breakage.

\section{Flocculation Experiments}

This part was presented in detail in the previous work by $\mathrm{Li}$ et al. [22]. Flocculation experiments were conducted in a mixing tank using aerobic activated sludge collected from a municipal wastewater treatment plant. Average velocity gradient was set in the range of $28.2 \sim 149.8 \mathrm{~s}^{-1}$ by adjusting the stirring speed $\left(80 \sim 280 \mathrm{r} \cdot \mathrm{min}^{-1}\right)$. FSDs of activated sludge during flocculation were measured using a laser particle size analyzer (S3500, Microtrac). Two-dimensional fractal dimension $\mathrm{D}_{2}$ of activated sludge was determined based on microscopy and image analysis. The relationship between maximum diameter (i.e., circumscribed circle diameter) $L_{c}$ (i) and equivalent diameter $L_{i}$ can be written as

$$
\begin{gathered}
\left(\frac{L_{c}(i)}{L_{P}}\right)^{D_{2}} \approx \frac{A_{i}}{A_{P}}=\left(\frac{L_{i}}{L_{P}}\right)^{2} \Longrightarrow \\
L_{c}(i) \approx\left(\frac{L_{i}}{L_{P}}\right)^{2 / D_{2}} L_{P}
\end{gathered}
$$

where $L_{P}$ is the primary particle size, $A_{i}$ is the area of floc in class $i$, and $A_{P}$ is the area of the primary particle.

\section{Model Description}

The discretized population balance model developed by Kumar \& Ramkrishna [28] is used to describe the variation rate in the number of flocs with a given size during activated sludge flocculation

$$
\begin{aligned}
\frac{d N_{i}}{d t}= & \sum_{\substack{j, k \\
v_{i-1} \leq\left(v_{j}+v_{k}\right) \leq v_{i+1}}}^{j \geq k}\left[1-\frac{1}{2} \delta_{j, k}\right] \eta_{i} \alpha \beta(j, k) N_{j} N_{k} \\
& -N_{i} \sum_{k} \alpha \beta(i, k) N_{k}+\sum_{j \geq i} \gamma_{j, i} S(j) N_{j}-S(i) N_{i}
\end{aligned}
$$

where $N_{i}$ is the number concentration of flocs in class $i, v_{i}$ is the volume of flocs in class $i, \delta_{j, k}$ is Dirac delta function, $\alpha$ is the collision efficiency, $\beta(j, k)$ is the collision frequency of flocs in class $j$ and $k, S(i)$ is the breakage rate of flocs in class $i, \gamma_{j, i}$ is the breakage distribution function defining the fraction of daughter-particle in class size $i$ breaking from a floc in class size $j$, and $\eta_{i}$ is a proportional coefficient assigning the fraction of the floc $v_{i}$ from the aggregate $\left(v_{j}+v_{k}\right)$ :

$$
\eta_{i}= \begin{cases}\frac{v_{i+1}-\left(v_{j}+v_{k}\right)}{v_{i+1}-v_{i}} & v_{i} \leq\left(v_{j}+v_{k}\right) \leq v_{i+1} \\ \frac{\left(v_{j}+v_{k}\right)-v_{i-1}}{v_{i}-v_{i-1}} & v_{i-1} \leq\left(v_{j}+v_{k}\right) \leq v_{i}\end{cases}
$$

3.1. Collision Efficiency. The collision efficiency represents the probability that two flocs stay together after colliding. Generally, the collision efficiency is considered to be constant with a value of $0 \sim 1$ or a function of the sizes of the two colliding particles [29]. The function proposed by Pruppacher and Klett [30], in which the sticking probability between any two particles is related to the difference of their motion speed which depends on their sizes, has been successfully used to calculate the collision efficiency of natural flocs [31]. In this study, the function was modified as follows:

$$
\alpha_{i, j}=\alpha_{\max }\left(\frac{L_{i} / L_{j}}{1+L_{i} / L_{j}}\right)^{2}
$$

where $\alpha_{\max }$ is a calibration parameter.

3.2. Collision Frequency. The collision frequency due to shear rate has usually been considered as a function of particle size $[2,6]$. Considering that the maximum size determines the interactions between flocs more directly, the collision frequency can be calculated from

$$
\begin{aligned}
\beta(i, j) & =\frac{G}{6}\left(L_{c}(i)+L_{c}(j)\right)^{3} \\
& =\frac{G}{6}\left(\left(\frac{L_{i}}{L_{P}}\right)^{2 / D_{2}} L_{P}+\left(\frac{L_{j}}{L_{P}}\right)^{2 / D_{2}} L_{P}\right)^{3}
\end{aligned}
$$

where $G$ is the average velocity gradient,

$$
G=\left(\frac{\varepsilon}{\nu}\right)^{1 / 2}
$$


TABLE 1: Four models with different expressions for the aggregation and breakage of activated sludge.

Collision efficiency Aggregation frequency Breakage rate* Daughter-particles distribution Parameters need to be calibrated

\begin{tabular}{|c|c|c|c|c|c|}
\hline Method 1 & constant & \multirow{4}{*}{ Eq. (5) } & Eq. (7) & binary & $\alpha_{\text {cons }}, E$ \\
\hline Method 2 & constant & & Eq. (7) & \multirow{3}{*}{ binomial } & $\alpha_{\text {cons }}, E$ \\
\hline Method 3 & Eq. (4) & & Eq. (7) & & $\alpha_{0}, E$ \\
\hline Method 4 & Eq. (4) & & Eq. (10) & & $\alpha_{0}, E, S_{\max }$ \\
\hline
\end{tabular}

where $\varepsilon$ represents the homogeneous turbulent energy dissipation rate of the mixed tank and $v$ is the kinematic viscosity of the suspending fluid.

3.3. Breakage Rate. The breakage of aggregates is mainly caused by hydrodynamic stress acting on the aggregates, and the breakage rate is always assumed to be relating to particle size $[3,6]$. Considering that the maximum size determines the floc breakage behaviors more directly, then

$$
S(i)=E L_{c}(i)=E\left(\frac{L_{i}}{L_{P}}\right)^{2 / D_{2}} L_{P}
$$

where $E$ is the breakage rate coefficient relating to the shear rate.

Eq. (8), namely, the traditional expression for breakage rate, demonstrates that the breakage rate is simply proportional to floc size. However, the Kusters [27] expression shows a different feature of the breakage rate that increases with the increasing floc size towards a final maximum [4]:

$$
S(i)=\left(\frac{4}{15 \pi}\right)^{1 / 2}\left(\frac{\varepsilon}{\nu}\right)^{1 / 2} \exp \left(-\frac{\varepsilon_{b i}}{\varepsilon}\right)
$$

where $\varepsilon_{b i}$ is the critical turbulent energy dissipation rate at which flocs start the breakage and is related to floc size

$$
\varepsilon_{b i}=\frac{B}{L_{c}(i)}=\frac{B}{\left(L_{i} / L_{P}\right)^{2 / D_{2}} L_{P}}
$$

where $B$ is a fitting parameter.

Taking these two expressions together into account, the traditional expression can be modified by setting a final maximum value for the breakage rate:

$$
S(i)
$$

$$
= \begin{cases}E\left(\frac{L_{i}}{L_{P}}\right)^{2 / D_{2}} L_{P} & E\left(\frac{L_{i}}{L_{P}}\right)^{2 / D_{2}} L_{P}<S_{\max } \\ S_{\max } & E\left(\frac{L_{i}}{L_{P}}\right)^{2 / D_{2}} L_{P} \geq S_{\max }\end{cases}
$$

where $S_{\max }$ is the maximum breakage rate.

3.4. Breakage Distribution Function. In terms of daughterparticles distribution, the simple binary breakage function and the normal breakage function are mostly used $[2,3$, 5]. As a uniform computational grid, i.e., $v_{i}=i v_{P}\left(v_{P}\right.$ is the volume of the primary particle), was used to solve the population balance model, the normal breakage function could be approximated to a binomial breakage function. Therefore, $\gamma_{j, i}$ can be calculated from Eq. $(12)[6,11]$ :

$$
\gamma_{j, i}=\frac{\left(\begin{array}{c}
j \\
i
\end{array}\right)}{\sum_{i=1}^{j}\left(\begin{array}{l}
j \\
i
\end{array}\right)}
$$

According to Eq. (8) the higher probability of daughterparticle distribution would occur when the volume of daughter-particle is close to half of the original-particle. The normal breakage function is superior to the binary breakage function, as the former indicates a probability of daughter-particles distribution. However, the calculation load of a uniform computational grid is comparatively large while the floc size range is wide (e.g., $5 \sim 1000 \mu \mathrm{m})$. For a geometric grid with factor $k\left(v_{i}=k v_{i-1}, 1<k \leq 2\right)$ adopted to solve the population balance model, a binomial breakage function in another form can be used for the daughterparticle distribution (see Appendix A of Li et al. [32]):

$$
\gamma_{j, i}=\left(\begin{array}{l}
j \\
i
\end{array}\right) p^{i}(1-p)^{j-i} \quad(i=1,2, \ldots, j)
$$

The shape of a binomial distribution is determined by class number $j$ and parameter $p$, and the probability mass function reaches its peak at the location $j \times p$. Defining the parameter $C_{p}$ to determine the location at which the probability mass function reaches its peak, then

$$
p=\frac{\left(i-C_{p}\right)}{i}
$$

Assuming that the daughter-particle whose volume is the half of the original floc volume has the highest probability, $C_{p}$ can be calculated from

$$
C_{p}=\frac{\log (2)}{\log (k)}
$$

3.5. Modelling Method. In order to investigate the applicability of modified expressions for collision efficiency, breakage rate, and binomial distribution, especially compared with that of traditional expressions (i.e., constant collision efficiency, size-dependent breakage rate, and binary distribution), four methods were used to simulate the time evolution of FSD during activated sludge flocculation (see Table 1) and their effectiveness was compared.

The initial number concentrations of the models were generated by transforming the volume distribution data coming from the laser particle size analyzer to a number distribution [22]. A geometric grid with factor 1.6 was used, i.e., $v_{i} \approx 1.6 v_{i-1}$, aligning with the Fibonacci series rule $v_{i}+$ $v_{i-1} \approx v_{i+1}$. The binary distribution (in Table 1) was treated by using a simple technique similar to the fixed pivot technology 


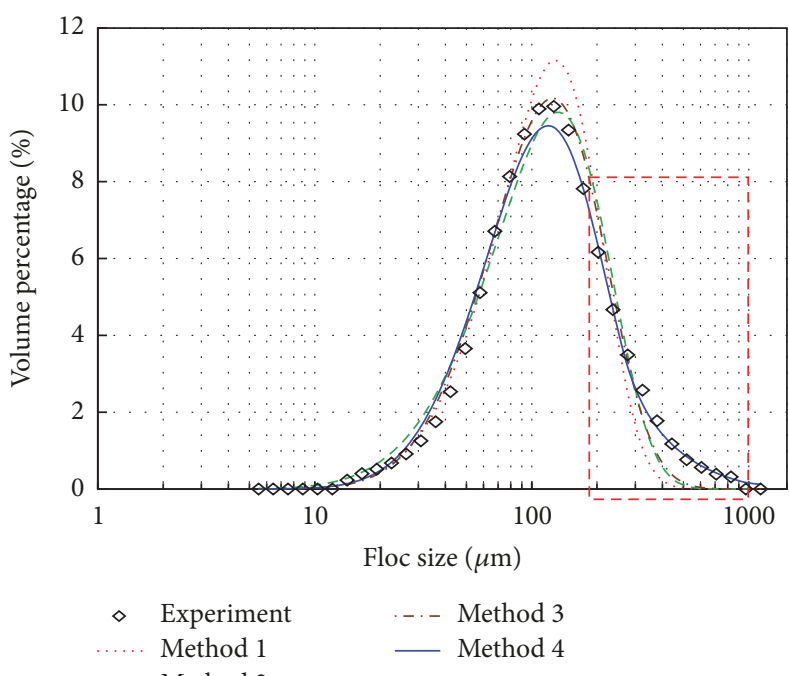

(a) $G=28.2 \mathrm{~s}^{-1}$

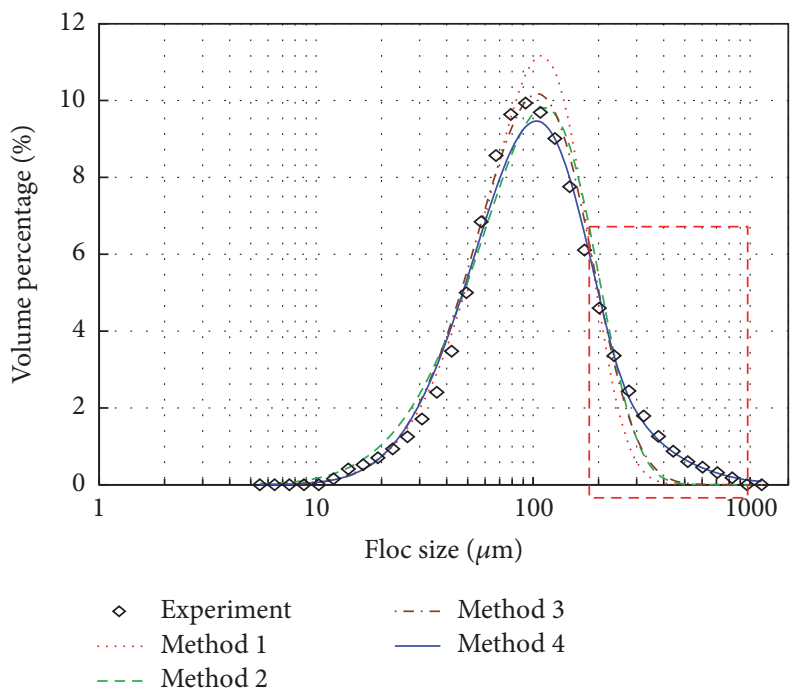

(c) $G=101.7 \mathrm{~s}^{-1}$

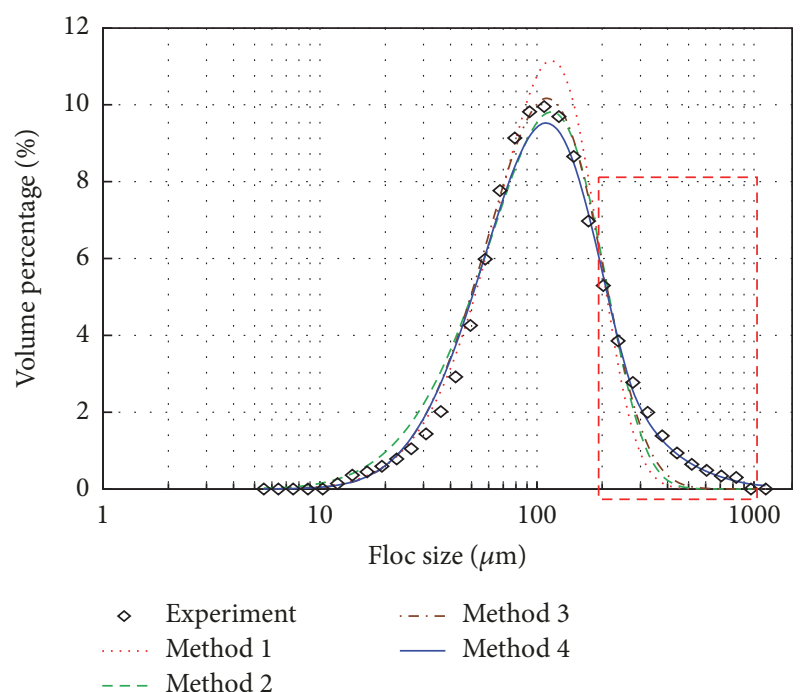

(b) $G=64.7 \mathrm{~s}^{-1}$

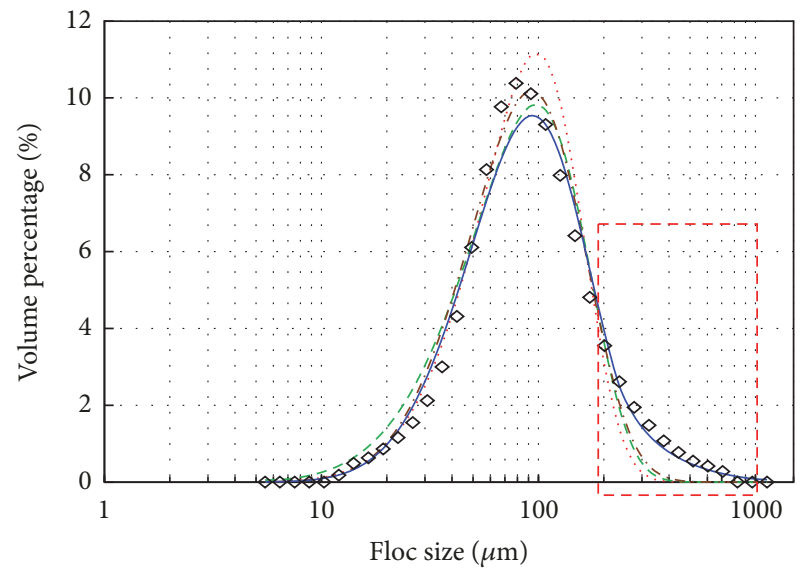

Experiment $\quad-\cdot \operatorname{Method} 3$
$\cdots$

- - Method 2

Figure 1: Simulated steady-state floc size distribution by using the four models under different velocity gradients (simulation results in the previous paper [22] were shown in Method 2).

proposed by Kumar and Ramkrishna [28]. Assuming that the floc with volume $v_{i}$ breaks up into two equal-size daughterparticles, the newly formed floc is represented by assigning proportional fractions to the flocs with volume $v_{\mathrm{i}-2}$ and $v_{\mathrm{i}-1}$.

The integration of Eq. (1) involved computing the discrete $\Delta N_{i} / \Delta t$ of $\mathrm{dN}_{i} / \mathrm{d} t$ values. The iterative calculation of $\Delta t$ was set as $0.1 \sim 1$ s to maintain calculation stability. The minimum error method was used for the parameter calibration:

$$
\operatorname{Err}_{1}=\frac{1}{m} \frac{1}{n} \sum_{t=t_{1}}^{t_{\mathrm{m}}} \sum_{i=1}^{n}\left|m(t, i)-m^{\prime}(t, i)\right|
$$

where $m(t, i)$ and $m^{\prime}(t, i)$ are the measured and simulated volume percentage of flocs in class $i$ at time $t$, respectively. $t_{1}$ and $t_{\mathrm{m}}$ are the start and end time of the flocculation process, respectively. The error of mean floc size was defined as

$$
E r r_{2}=\frac{1}{m} \sum_{t=t_{1}}^{t_{\mathrm{m}}}\left|L_{\text {mean }}(t)-L_{\text {mean }}{ }^{\prime}(t)\right|
$$

where $L_{\text {mean }}(t)$ and $L_{\text {mean }}{ }^{\prime}(t)$ are the measured and simulated volume mean floc size at time $t$, respectively, and

$$
L_{\text {mean }}=\frac{\sum_{i} L_{i} V_{i}}{\sum_{i} V_{i}}
$$

where $V_{i}$ is the total volume of flocs in class $i$.

\section{Results and Discussion}

4.1. Simulation Results of FSDs. During the activated sludge flocculation process, the FSD (in the range of $5.5 \sim 1132 \mu \mathrm{m}$ ) initially increases and finally reaches the steady-state values after about $30 \mathrm{~min}$. Method 1 and method 2 produce similar steady-state FSDs (Figure 1), and the calibrated values of 
TABLE 2: Results of parameters calibration and modeling errors of four methods.

\begin{tabular}{|c|c|c|c|c|c|c|c|}
\hline & & $\begin{array}{l}\text { Constant for } \\
\text { collision } \\
\text { efficiency } \\
\left(\alpha_{\text {cons }}\right)\end{array}$ & $\begin{array}{l}\text { Parameter of } \\
\text { Eq. }(3) \text { for } \\
\text { collision } \\
\text { efficiency } \\
\left(\alpha_{\max }\right) \\
\end{array}$ & $\begin{array}{c}\text { breakage rate } \\
\text { coefficient } \\
\left(E, \mathrm{~m}^{-1} \cdot \mathrm{s}^{-1}\right)\end{array}$ & $\begin{array}{c}\text { maximum } \\
\text { breakage rate } \\
{ }^{*}\left(S_{\max }, s^{-1}\right)\end{array}$ & $\begin{array}{l}\text { Average error } \\
\text { of volume } \\
\text { percentage } \\
\left(E r r_{1}, \%\right)\end{array}$ & $\begin{array}{c}\text { Average error } \\
\text { of mean size } \\
\left(E r r_{2}, \mu \mathrm{m}\right)\end{array}$ \\
\hline \multirow{4}{*}{$G=28.2 \mathrm{~s}^{-1}$} & Method 1 & 0.33 & & 363 & & $4.67 \times 10^{-1}$ & 18.86 \\
\hline & Method 2 & 0.32 & & 328 & & $4.51 \times 10^{-1}$ & 15.07 \\
\hline & Method 3 & & 0.58 & 271 & & $3.17 \times 10^{-1}$ & 13.86 \\
\hline & Method 4 & & 0.78 & 389 & 0.16 & $2.25 \times 10^{-1}$ & 0.69 \\
\hline \multirow{4}{*}{$G=64.7 \mathrm{~s}^{-1}$} & Method 1 & 0.21 & & 573 & & $4.76 \times 10^{-1}$ & 16.01 \\
\hline & Method 2 & 0.23 & & 593 & & $4.54 \times 10^{-1}$ & 15.76 \\
\hline & Method 3 & & 0.30 & 351 & & $3.38 \times 10^{-1}$ & 13.42 \\
\hline & Method 4 & & 0.34 & 413 & 0.16 & $2.48 \times 10^{-1}$ & 0.52 \\
\hline \multirow{4}{*}{$G=101.7 \mathrm{~s}^{-1}$} & Method 1 & 0.09 & & 405 & & $4.95 \times 10^{-1}$ & 16.77 \\
\hline & Method 2 & 0.09 & & 381 & & $4.79 \times 10^{-1}$ & 14.49 \\
\hline & Method 3 & & 0.16 & 310 & & $3.51 \times 10^{-1}$ & 13.46 \\
\hline & Method 4 & & 0.22 & 447 & 0.16 & $2.47 \times 10^{-1}$ & 0.36 \\
\hline \multirow{4}{*}{$G=149.8 \mathrm{~s}^{-1}$} & Method 1 & 0.05 & & 362 & & $5.58 \times 10^{-1}$ & 15.46 \\
\hline & Method 2 & 0.05 & & 350 & & $5.62 \times 10^{-1}$ & 16.34 \\
\hline & Method 3 & & 0.08 & 252 & & $4.33 \times 10^{-1}$ & 14.62 \\
\hline & Method 4 & & 0.15 & 481 & 0.16 & $3.58 \times 10^{-1}$ & 0.23 \\
\hline
\end{tabular}

*: The fractal dimension $D_{2}=1.83$ was used in the expressions for the collision frequency and breakage rate. The maximum breakage rate, which is assumed to be independent on the velocity gradient, was calibrated to be 0.16 from the floc size distribution of activated sludge at the velocity gradient of $28.2,64.7,101.7$ and $149.8 \mathrm{~s}^{-1}$.

parameters $\alpha_{\text {cons }}$ and $E$ in the two models are very similar too (Table 2). This result might be attributed to the fact that the binomial distribution is not significantly different from the binary distribution as the binomial distribution parameter $C_{p}$ calculated from Eq. (14) results in the highest generation probability of daughter-particle whose volume equaled half of the original floc. However, the binomial distribution generated better fitting of FSD and mean size to the experimental data than the binary distribution except for $G=149.8 \mathrm{~s}^{-1}$ (see $\operatorname{Err}_{1}$ and $\mathrm{Err}_{2}$ in Table 2).

In Figure 1, compared to the constant collision efficiency used in method 2, the size-dependent collision efficiency adopted in method 3 improves the simulation results of the volume percentage of small flocs $(L<100 \mu \mathrm{m})$. However, no obvious improvement was observed for the volume percentage of large flocs $(L>200 \mu \mathrm{m})$. Consequently, the simulated mean floc sizes were also smaller than their measurements. Method 4 with the modified expression for breakage rate gave accurate simulation to the volume percentage distributions of large flocs at steady state, and the simulated mean floc size during the flocculation agrees well with the measured results. The simulated time evolution of FSD during the flocculation by using method 4 is more consistent with the experimental data than that by using method 2, which was used in our previous study (Figure 2).

The time evolution of the mean size of activated sludge flocs at different shear rates was shown in Figure 3. The flocculation of activated sludge under shear-induced conditions is a rapid process which would be close to end after about 10 minutes. The simulated mean sizes using method 4 display a better agreement with the experimental data, whereas those obtained by using the other three methods are smaller than the experimental data. This result is related to the simulations of the volume percentage of flocs, especially for the large flocs (about $L>200 \mu \mathrm{m}$ ). The volume percentages of the large flocs, despite being relatively small, make a significant contribution to the value of mean size calculated by Eq. (14).

4.2. Parameters of Flocculation Dynamics. The simulation results demonstrate the superiority of the collision efficiency relating to the size discrepancy (Eq. (4)) over a constant collision efficiency, as well as the binominal distribution over the binary distribution for daughter-particles. The previous studies have proved that the constant values of collision efficiency negatively relate to the average velocity gradient [19]. Furthermore, the constant value of collision efficiency (in methods 1 and 2) and the average value calculated by Eq. (4) (in methods 3 and 4) both display a power-law relationship with average velocity gradient and decrease with the rise of average velocity gradient (Figure 4).

The use of the traditional expression of breakage rate in methods 1, 2, and 3 generates smaller simulated mean sizes and volume percentages of large flocs (about $L>200 \mu \mathrm{m}$ ) than the experimental measurements. It might be due to the fact that the breakage rate of large flocs is overestimated by the traditional expression (Eq. (7)), in which the breakage rate is simply proportional to floc size. In fact, the Kusters [27] expression shows a different feature of the breakage rate 


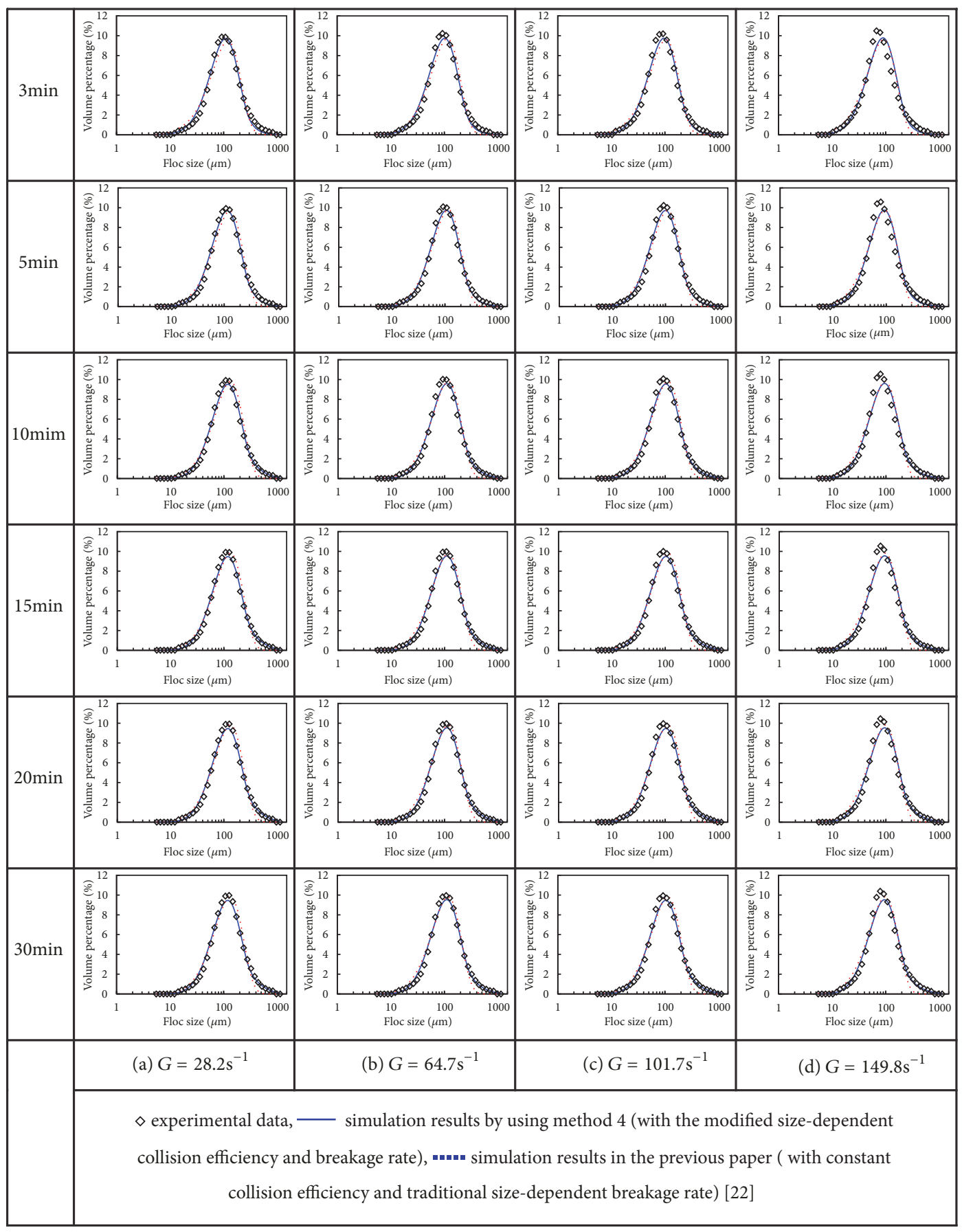

FIGURE 2: Simulation results of the evolution of floc size distribution at different velocity gradient by using method 4.

that increases with the increasing floc size towards a final maximum. However, the Kusters expression (Eq. (10)) with the introduction of a coefficient $K$ gave a better prediction for the volume percentages of large flocs (about $L>200 \mu \mathrm{m}$ ), but the worse prediction for small flocs (about $L<100 \mu \mathrm{m}$ ) than the traditional expression (Figure 5(a)). Moreover, it was found that, for small flocs (about $L<100 \mu \mathrm{m}$ ), the Kusters expression would give smaller breakage rates than the traditional expression (Figure 5(b)). Taking these two expressions together into account, this paper modified the traditional expression by setting a final maximum value for the breakage rate (in method 4). This modification improved the simulation results of FSD and mean size obviously, and it is suggested that the supposed maximum for the breakage rate might be independent on the velocity gradient.

Generally, the relationship between the breakage rate coefficient and the average velocity gradient has been proposed to follow a power law $[3,19]$. As the average velocity gradient increases, the breakage rate coefficient also increases. However, in this work, the breakage rate coefficient 


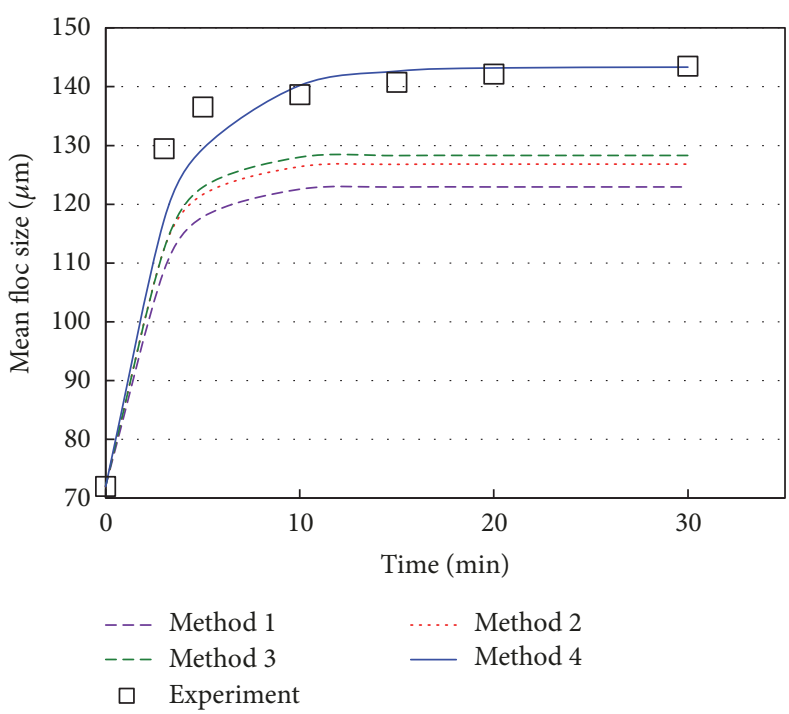

(a) $G=28.2 \mathrm{~s}^{-1}$

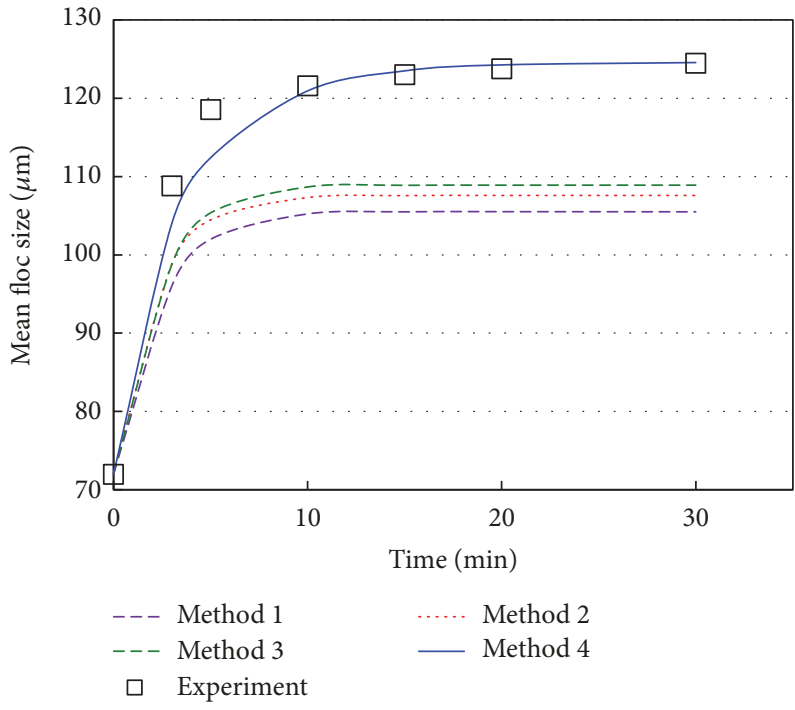

(c) $G=101.7 \mathrm{~s}^{-1}$

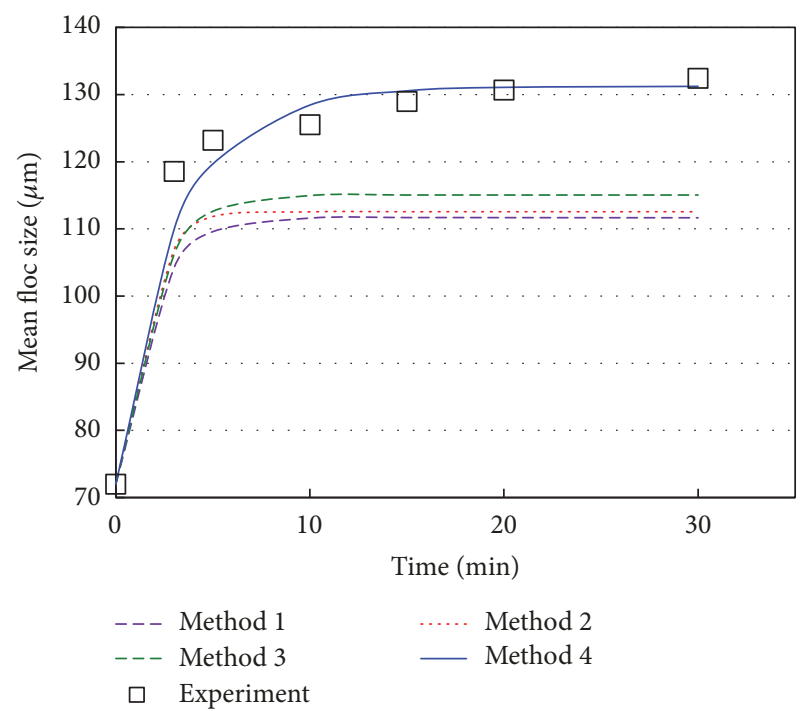

(b) $G=64.7 \mathrm{~s}^{-1}$

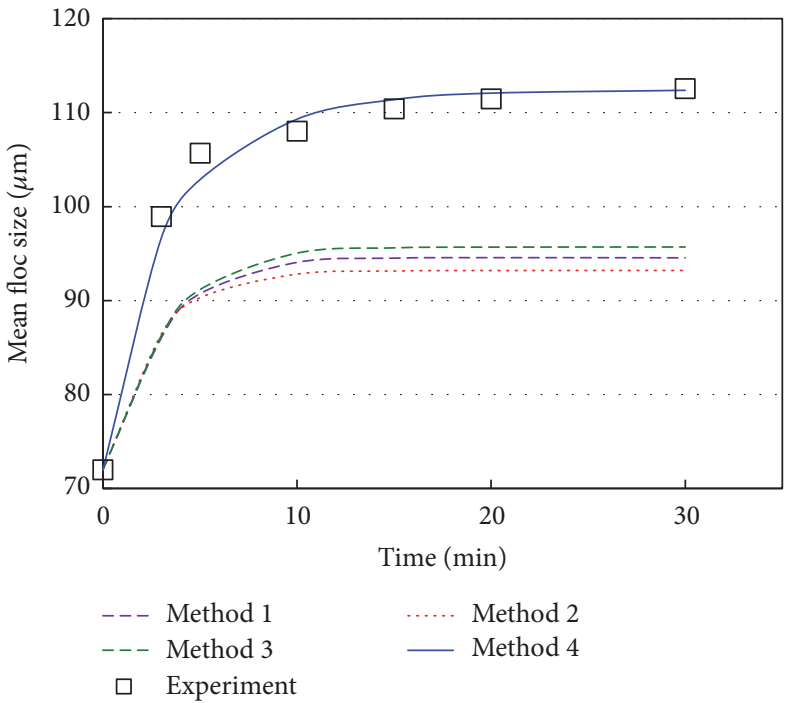

(d) $G=149.8 \mathrm{~s}^{-1}$

FIGURE 3: Simulation results of mean floc size of four methods under different velocity gradients.

$E$ calibrated in methods 1,2, and 3 does not follow the relationships (Figure 6). This result might relate to the fact that the parameters are estimated completely by the best fitting to the experimental data, without the consideration of the expected physical relationships between the dynamics parameters and shear rate. Additionally, the breakage rate coefficient of method 4 exhibits an obviously positive correlation with the average velocity.

\section{Conclusions}

This paper describes the application of PBM with modified expressions for the aggregation and breakage processes in the simulation of FSD (in the range of $5.5 \sim 1132 \mu \mathrm{m}$ ) in activated sludge flocculation process under shear-induced conditions (average velocity gradient of $28.2-149.8 \mathrm{~s}^{-1}$ ). The following conclusions were drawn:

(1) More accurate simulation of FSD in activated sludge flocculation could be obtained by using size-dependent collision efficiency and a binominal daughter-particles distribution function than using constant collision efficiency and the binary daughter-particles distribution, respectively.

(2) Compared to the traditional expression, in which the breakage rate is set to be proportional to floc size, the modified expression with a supposed maximum for the breakage rate improved the simulation results of FSD and mean size obviously.

(3) The collision efficiency and breakage rate coefficient show a power-law relationship with the average velocity gradient; the former decreases while the latter increases with the rise of the average velocity gradient, and the maximum 


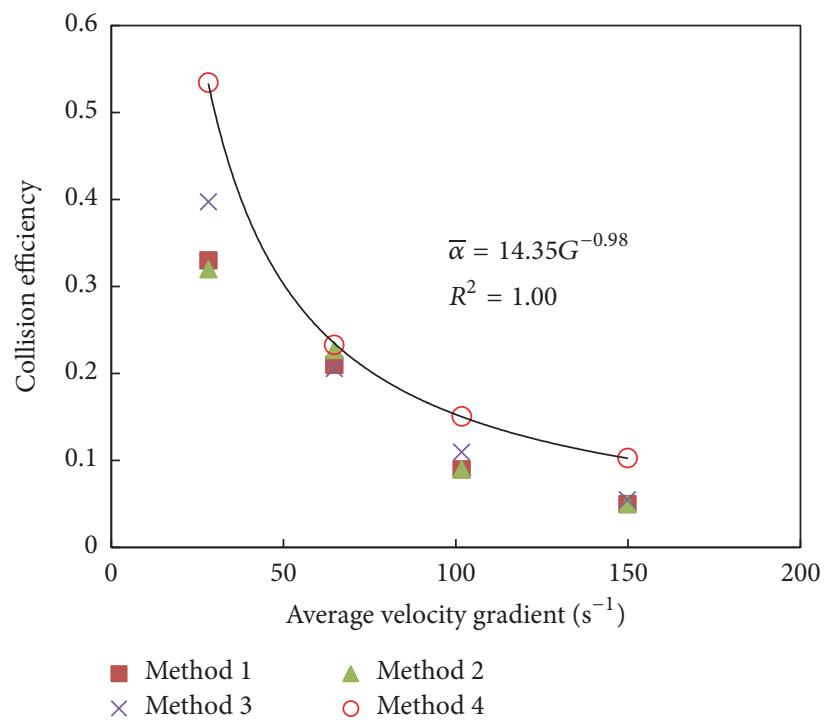

FIGURE 4: Relationship between collision efficiency and average velocity gradient (the average values of collision efficiency $\bar{\alpha}$ were calculated by Eq. (4) in methods 3 and 4 ).

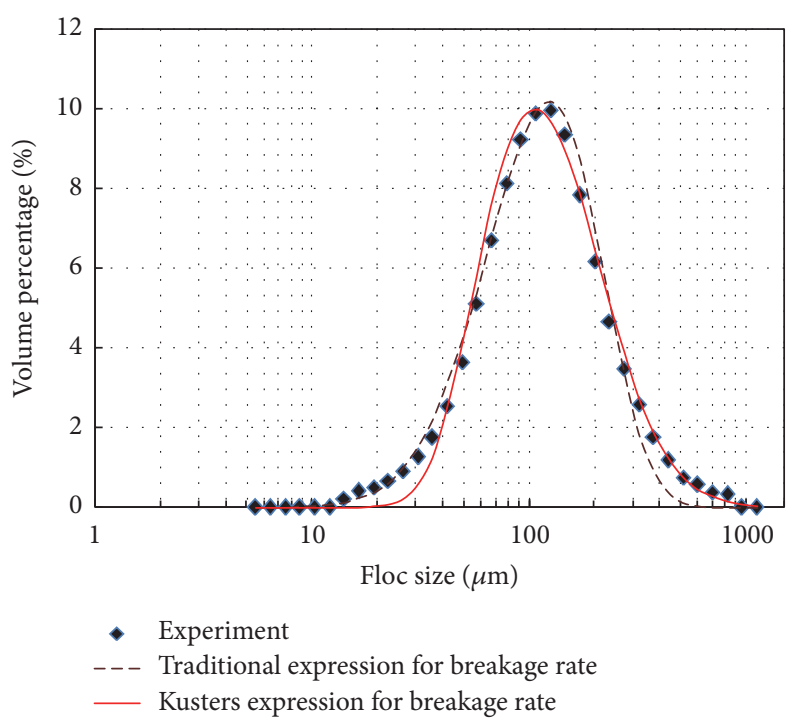

(a)

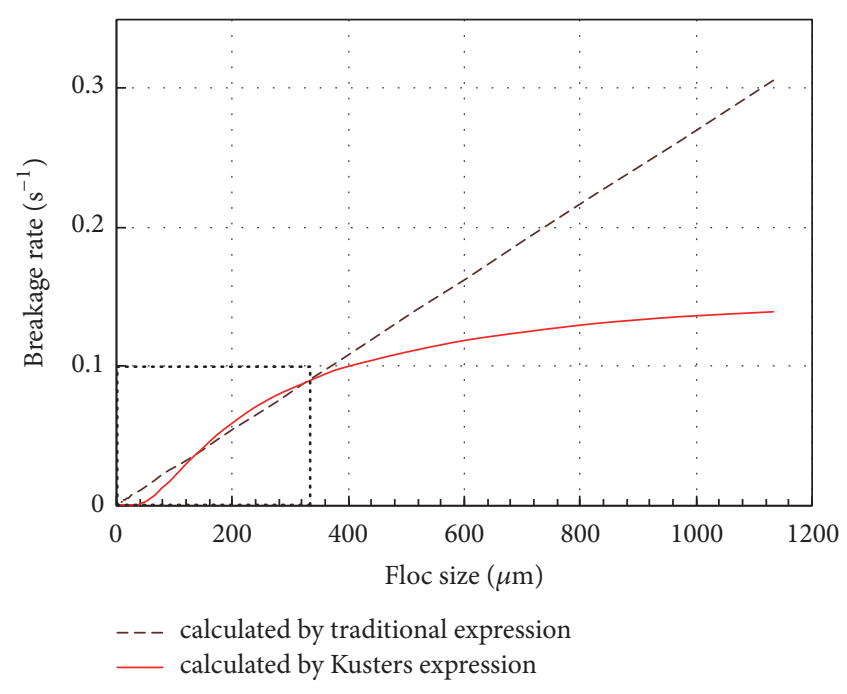

(b)

FIGURE 5: Comparisons of steady-state FSD simulation and breakage rate calculations using traditional expression (Eq. (7)) and Kusters [27] expression $\left(G=28.2 \mathrm{~s}^{-1}, \alpha_{0}=0.58, D_{2}=1.83, C_{p}=1.47, K=2.05 \times 10^{-2}\right.$, and $B=1.67 \times 10^{-7} \mathrm{~m}^{3} \cdot \mathrm{s}^{-3}$ for Eq. (8)).

breakage rate might be independent with the velocity gradient.

However, it should be noted that the determination of appropriate expressions for breakage and aggregation kernels in complex systems such as activated sludge is indeed a challenge, and the applicability of the suggested collision and breakage functions to other systems remains to be tested.

\section{Notation}

$A_{i}:$ Area of floc in class $i\left(\mathrm{~m}^{2}\right)$

$A_{P}$ : Area of the primary particle $\left(\mathrm{m}^{2}\right)$
B: $\quad$ Parameter in Eq. (9) $\left(\mathrm{m}^{3} \cdot \mathrm{s}^{-3}\right)$

$C_{p}$ : Binomial breakage function parameter

$D_{2}$ : Two-dimensional fractal dimension

E: $\quad$ Breakage rate coefficient $\left(\mathrm{m}^{-1} \cdot \mathrm{s}^{-1}\right)$

$G$ : $\quad$ Average velocity gradient $\left(\mathrm{s}^{-1}\right)$

$L: \quad$ Floc equivalent diameter $(\mu \mathrm{m})$

$L_{c}$ : $\quad$ Floc circumscribed circle diameter or maximum diameter $(\mu \mathrm{m})$

$L_{\text {mean }}:$ Volume mean size $(\mu \mathrm{m})$

$L_{P}: \quad$ Primary particle size $(\mu \mathrm{m})$

$K$ : $\quad$ Coefficient introduced into Kusters [27] expression for breakage rate 


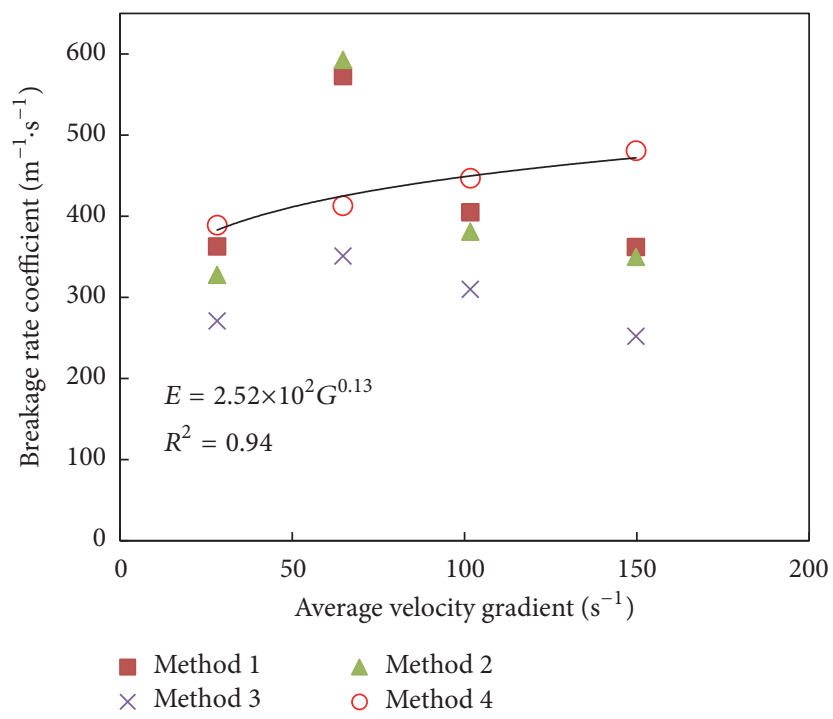

FIGURE 6: Relationship between breakage rate coefficient and average velocity gradient.

p: $\quad$ Parameter, see Eq. (13)

$N_{i}$ : Number concentration of flocs in class $i$ $\left(\mathrm{m}^{-3}\right)$

$S(i)$ : Breakage rate of flocs in class $i\left(\mathrm{~s}^{-1}\right)$

$v_{i}$ : Floc volume of flocs in class $i\left(\mathrm{~m}^{3}\right)$

$v_{P}$ : Volume of a fundamental particle $\left(\mathrm{m}^{3}\right)$

$V_{i}$ : Total volume of flocs in class $i\left(\mathrm{~m}^{3}\right)$

\section{Greek Letters}

$\alpha: \quad$ Collision efficiency

$\beta(j, k)$ : Collision frequency for flocs of class $j$ and $k\left(\mathrm{~m}^{3} \cdot \mathrm{s}^{-1}\right)$

$\gamma_{j, i}: \quad$ Breakage distribution function

$\delta_{j, k}: \quad$ Dirac Delta function

$\varepsilon: \quad$ Turbulent energy dissipation rate $\left(\mathrm{m}^{3} \cdot \mathrm{s}^{-2}\right)$

$\varepsilon_{b i}$ : Critical turbulent energy dissipation rate $\left(\mathrm{m}^{3} \cdot \mathrm{s}^{-2}\right)$

$\eta_{i}: \quad$ Coefficient, see Eq. (2)

$v$ : $\quad$ Kinematic viscosity $\left(\mathrm{m}^{2} \cdot \mathrm{s}^{-1}\right)$.

\section{Data Availability}

The experimental data used in this paper are available on request through first author: Zhenliang $\mathrm{Li}$ (zhenliangli@163.com).

\section{Conflicts of Interest}

The authors declare that they have no conflicts of interest.

\section{Acknowledgments}

The work was partially supported by Natural Science Foundation of China (51609028), Natural Science Foundation of
Chongqing (CSTC2016jcyjA0506), and Chongqing Postdoctoral Science Foundation (No. Xm2017141).

\section{References}

[1] I. Nopens, C. A. Biggs, B. De Clercq et al., "Modelling the activated sludge flocculation process combining laser light diffraction particle sizing and population balance modelling (PBM)," Water Science and Technology, vol. 45, no. 6, pp. 41-49, 2002.

[2] J.-J. Zhang and X.-Y. Li, "Modeling particle-size distribution dynamics in a flocculation system," AIChE Journal, vol. 49, no. 7, pp. 1870-1882, 2003.

[3] P. T. Spicer and S. E. Pratsinis, "Coagulation and fragmentation: universal steady-state particle-size distribution," AIChE Journal, vol. 42, no. 6, pp. 1612-1620, 1996.

[4] J. C. Flesch, P. T. Spicer, and S. E. Pratsinis, "Laminar and turbulent shear-induced flocculation of fractal aggregates," AIChE Journal, vol. 45, no. 5, pp. 1114-1124, 1999.

[5] R. I. Jeldres, F. Concha, and P. G. Toledo, "Population balance modelling of particle flocculation with attention to aggregate restructuring and permeability," Advances in Colloid and Interface Science, vol. 224, pp. 62-71, 2015.

[6] T. Serra and X. Casamitjana, "Modelling the aggregation and break-up of fractal aggregates in a shear flow," Applied Scientific Research, vol. 59, no. 2-3, pp. 255-268, 1998.

[7] C. Selomulya, G. Bushell, R. Amal, and T. D. Waite, "Understanding the role of restructuring in flocculation: The application of a population balance model," Chemical Engineering Science, vol. 58, no. 2, pp. 327-338, 2003.

[8] E. Antunes, F. A. P. Garcia, P. Ferreira, A. Blanco, C. Negro, and M. G. Rasteiro, "Modelling PCC flocculation by bridging mechanism using population balances: Effect of polymer characteristics on flocculation," Chemical Engineering Science, vol. 65, no. 12, pp. 3798-3807, 2010.

[9] J. Ducoste, "A two-scale PBM for modeling turbulent flocculation in water treatment processes," Chemical Engineering Science, vol. 57, no. 12, pp. 2157-2168, 2002. 
[10] C. Coufort, D. Bouyer, A. Liné, and B. Haut, "Modelling of flocculation using a population balance equation," Chemical Engineering and Processing: Process Intensification, vol. 46, no. 12, pp. 1264-1273, 2007.

[11] F. Maggi, F. Mietta, and J. C. Winterwerp, "Effect of variable fractal dimension on the floc size distribution of suspended cohesive sediment," Journal of Hydrology, vol. 343, no. 1-2, pp. 43-55, 2007.

[12] X. Shen and J. P.-Y. Maa, "Modeling floc size distribution of suspended cohesive sediments using quadrature method of moments," Marine Geology, vol. 359, pp. 106-119, 2015.

[13] F. Xu, D.-P. Wang, and N. Riemer, "Modeling flocculation processes of fine-grained particles using a size-resolved method: comparison with published laboratory experiments," Continental Shelf Research, vol. 28, no. 19, pp. 2668-2677, 2008.

[14] F. Mietta, C. Chassagne, R. Verney, and J. C. Winterwerp, "On the behavior of mud floc size distribution: model calibration and model behavior," Ocean Dynamics, vol. 61, no. 2-3, pp. 257271, 2011.

[15] B. J. Lee, E. Toorman, and M. Fettweis, "Multimodal particle size distributions of fine-grained sediments: Mathematical modeling and field investigation," Ocean Dynamics, vol. 64, no. 3, pp. 429-441, 2014.

[16] B. Wilén, B. Jin, and P. Lant, “The influence of key chemical constituents in activated sludge on surface and flocculating properties," Water Research, vol. 37, no. 9, pp. 2127-2139, 2003.

[17] G.-P. Sheng, H.-Q. Yu, and X.-Y. Li, "Extracellular polymeric substances (EPS) of microbial aggregates in biological wastewater treatment systems: A review," Biotechnology Advances, vol. 28, no. 6, pp. 882-894, 2010.

[18] H. Li, Y. Wen, A. Cao, J. Huang, Q. Zhou, and P. Somasundaran, "The influence of additives ( $\mathrm{Ca} 2+, \mathrm{Al} 3+$, and $\mathrm{Fe} 3+$ ) on the interaction energy and loosely bound extracellular polymeric substances (EPS) of activated sludge and their flocculation mechanisms," Bioresource Technology, vol. 114, pp. 188-194, 2012.

[19] C. A. Biggs and P. A. Lant, "Modelling activated sludge flocculation using population balances," Powder Technology, vol. 124, no. 3, pp. 201-211, 2002.

[20] I. Nopens, T. Koegst, K. Mahieu, and P. A. Vanrolleghem, "Population balance model and activated sludge flocculation: from experimental data to a calibrated model," AIChE Journal, vol. 51, no. 5, pp. 1548-1557, 2005.

[21] A. Ding, M. J. Hounslow, and C. A. Biggs, "Population balance modelling of activated sludge flocculation: Investigating the size dependence of aggregation, breakage and collision efficiency," Chemical Engineering Science, vol. 61, no. 1, pp. 63-74, 2006.

[22] Z. Li, D. Zhang, P. Lu, G. Chen, and H. Jiang, "Population balance model and calibration method for simulating the time evolution of floc size distribution of activated sludge flocculation," Desalination and Water Treatment, vol. 67, pp. 4150, 2017.

[23] I. Nopens, N. Nere, P. A. Vanrolleghem, and D. Ramkrishna, "Solving the inverse problem for aggregation in activated sludge flocculation using a population balance framework," Water Science and Technology, vol. 56, no. 6, pp. 95-103, 2007.

[24] E. Torfs, G. Bellandi, and I. Nopens, "Towards mechanistic models for activated sludge flocculation under different conditions based on inverse problems," Water Science and Technology, vol. 65, no. 11, pp. 1946-1953, 2012.

[25] E. Torfs, A. Dutta, and I. Nopens, "Investigating kernel structures for Ca-induced activated sludge aggregation using an inverse problem methodology," Chemical Engineering Science, vol. 70, pp. 176-187, 2012.

[26] I. Nopens, E. Torfs, J. Ducoste, P. A. Vanrolleghem, and K. V. Gernaey, "2015 Population balance model: a useful compementary modelling framework for future WWTP modelling," Water Science \& Technology, vol. 71, no. 2, pp. 159-167, 2015.

[27] K. Kusters, The influence of turbulence on aggregation of small particles in agitated vessels [Ph.D. thesis], Eindhoven University of Technology, Eindhoven, The Netherlands, 1991.

[28] S. Kumar and D. Ramkrishna, "On the solution of population balance equations by discretization- I. A fixed pivot technique," Chemical Engineering Science, vol. 51, no. 8, pp. 1311-1332, 1996.

[29] D. N. Thomas, S. J. Judd, and N. Fawcett, "Flocculation modelling: a review," Water Research, vol. 33, no. 7, pp. 1579-1592, 1999.

[30] H. R. Pruppacher and J. D. Klett, The Microphysics of Clouds and Precipitation, Reidel Publishing Company Press, Dordrecht, Holland, 1978.

[31] F. Maggi, Flocculation Dynamics of Cohesive Sediment, Delft University of Technology, Delft, the Netherlands, 2005.

[32] Z. Li, P. Lu, D. Zhang, G. Chen, S. Zeng, and Q. He, "Population balance modeling of activated sludge flocculation: investigating the influence of Extracellular Polymeric Substances (EPS) content and zeta potential on flocculation dynamics," Separation and Purification Technology, vol. 162, pp. 91-100, 2016. 


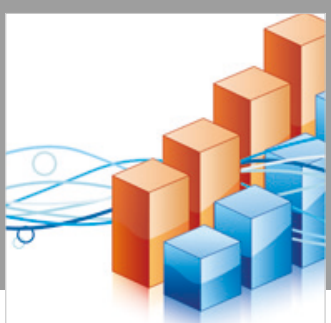

Advances in

Operations Research

\section{-n-m}
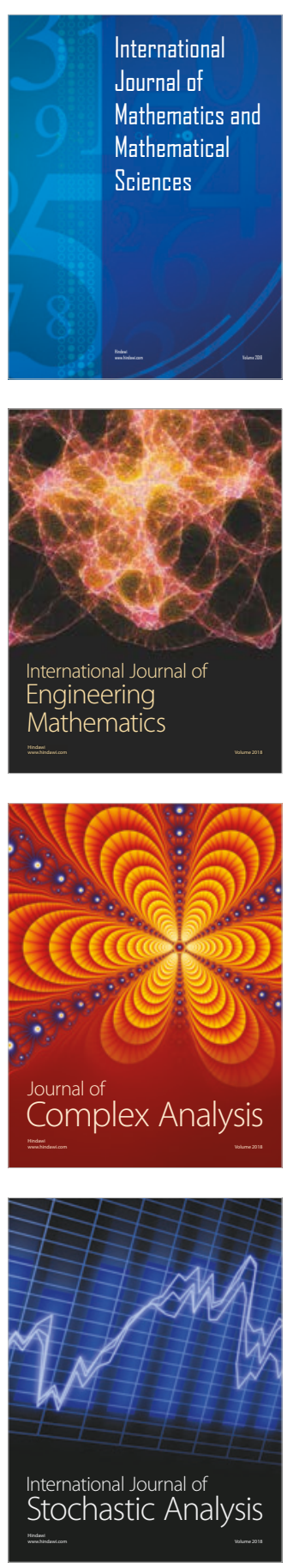
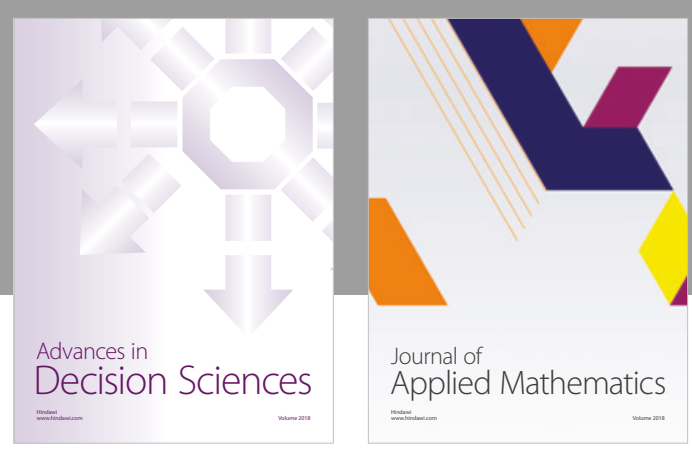

Journal of

Applied Mathematics
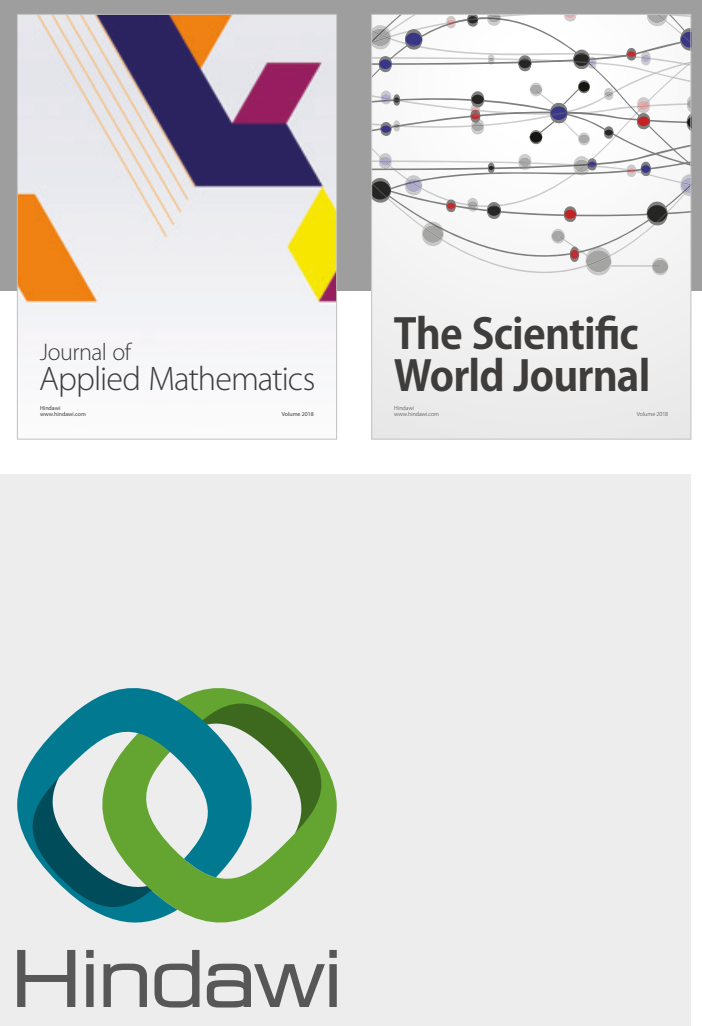

Submit your manuscripts at

www.hindawi.com

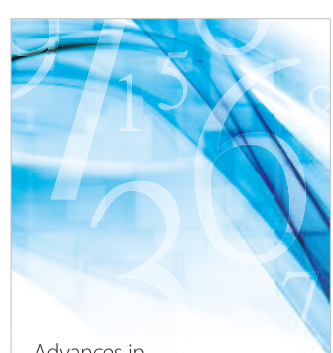

Advances in
Numerical Analysis
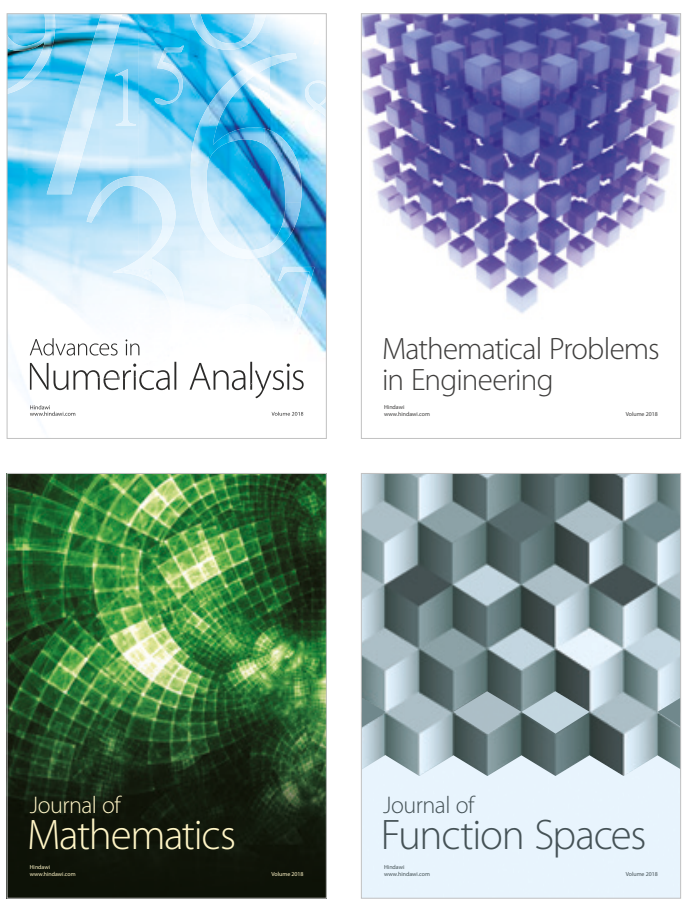

Mathematical Problems in Engineering

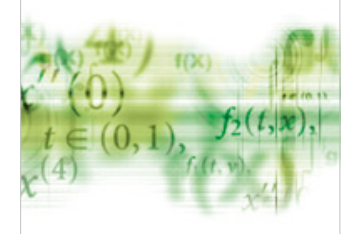

International Journal of

Differential Equations

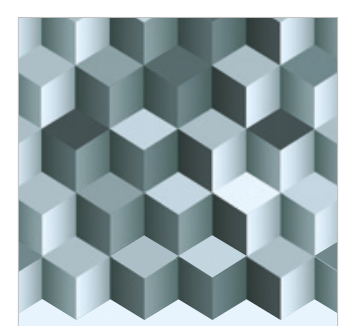

Journal of

Function Spaces

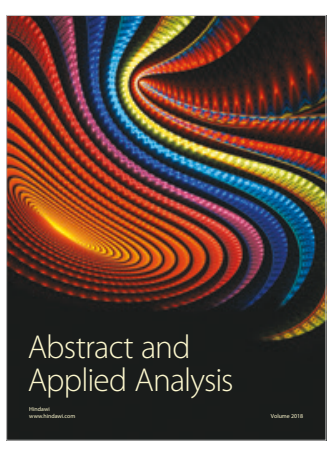

The Scientific

World Journal

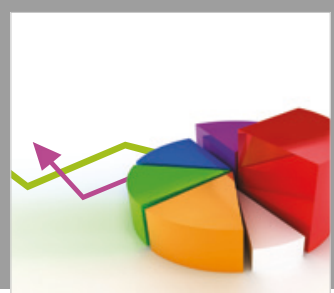

Journal of

Probability and Statistics
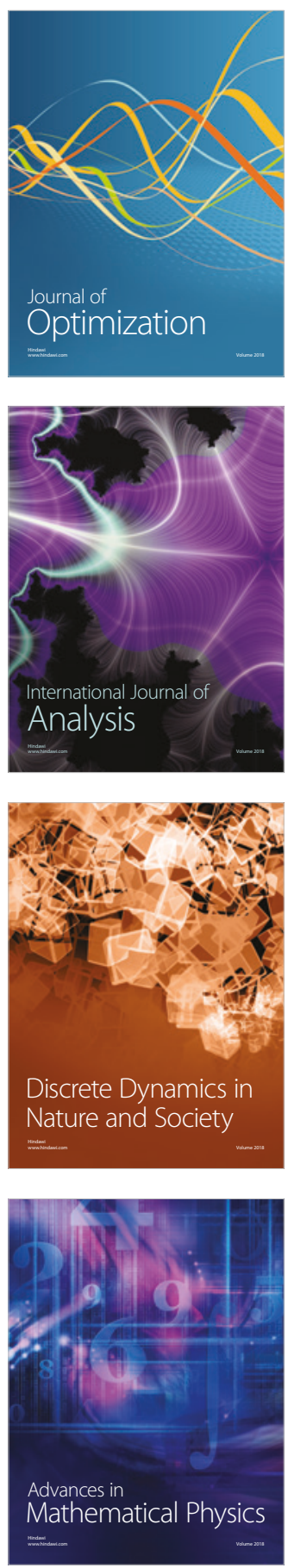